\title{
Angiotensin converting enzyme inhibitor induced hyperkalaemic paralysis
}

\author{
D Dutta, $M$ Fischler, A McClung
}

\begin{abstract}
Secondary hyperkalaemic paralysis is a rare condition often mimicking the Guillain-Barré syndrome. There have been a few case reports of hyperkalaemia caused by renal failure, trauma, and drugs where the presentation has been with muscle weakness. A case of hyperkalaemic paralysis caused by an angiotensin converting enzyme inhibitor is reported. (Postgrad Med f 2001;77:114-115)
\end{abstract}

Keywords: hyperkalaemia; paralysis; ACE inhibitors

Hyperkalaemia can cause muscle paralysis in two distinct ways. Hyperkalaemic periodic paralysis is an autosomal dominant sodium channel disorder of muscle attributable to a chromosomal mutation. ${ }^{1}$ Slightly less well known is a condition called secondary hyperkalaemic paralysis where an abnormally high serum potassium concentration due to various causes can lead to flaccid paralysis. A recent review identified a total of 18 cases reported in the world literature. ${ }^{2}$ No cases have yet been reported to the Committee on Safety of Medicines in the UK. Hyperkalaemia leading to paralysis has been reported in renal failure, ${ }^{34}$ trauma, ${ }^{56}$ spironolactone intake, ${ }^{278}$ treatment with amiloride/hydrochlorthiazide, ${ }^{9}{ }^{10}$ and trimethoprim-sulfamethoxazole therapy. ${ }^{11} \mathrm{We}$ describe what we believe to be the first reported case of hyperkalaemic paralysis secondary to treatment with an angiotensin converting enzyme (ACE) inhibitor.

\section{Submitted 17 January 2000 Accepted 18 May 2000 \\ Medicine, \\ General Hospital \\ Bewdley Road, \\ DY11 6RJ, UK \\ D Dutta \\ M Fischler \\ A McClung \\ Correspondence to: Dr McClung}

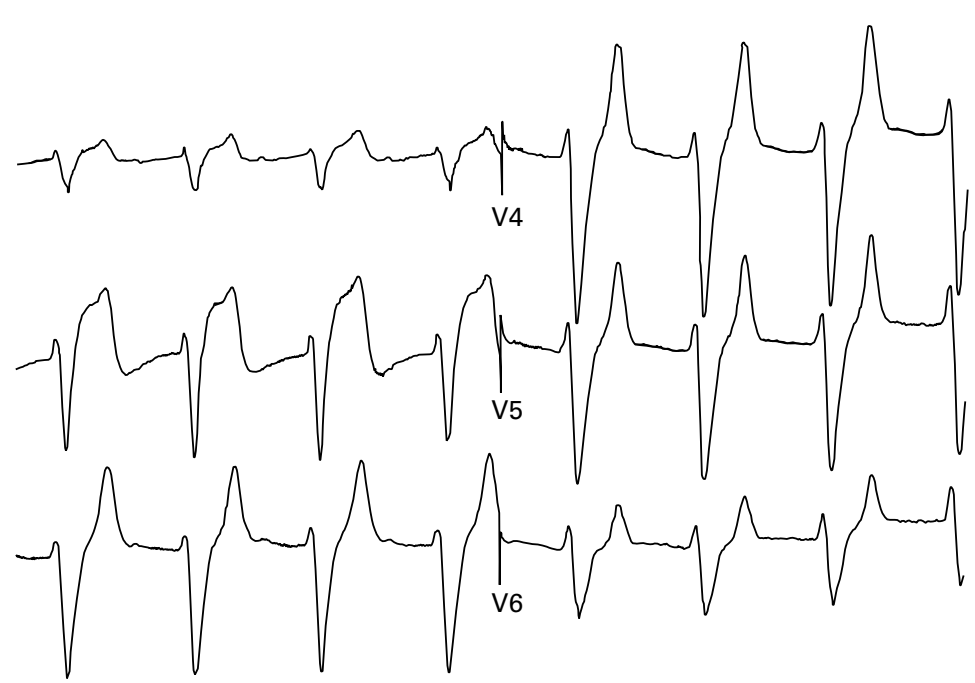

Figure 1 ECG on admission demonstrating tall peaked $T$ waves, widened $Q R S$ complexes, and diminished amplitude of $p$ waves characteristic of hyperkalaemia.

\section{Case report}

A 78 year old man was admitted after an acute onset of weakness of all four limbs. He had been well on the morning of admission and was driving his car when his limbs suddenly started feeling heavy. When first seen in casualty, he was unable to walk unaided, having a grade $3 / 5$ weakness in both upper and lower limbs. Cranial nerves were intact and fundi were normal. He had some subjective sensation of tingling and numbness in his arms but there was no objective sensory loss. His sphincters were not affected. Reflexes were found to be diminished uniformly and both plantars were downgoing. His pulse was regular and blood pressure normal. Examination of the heart, lungs, and abdomen was unremarkable.

He had a past medical history of ischaemic heart disease, cardiac failure, mild chronic renal impairment, and a previous ileostomy for ulcerative colitis. He was on enalapril $10 \mathrm{mg}$, which had been started in August 1995, frusemide (furosemide) $40 \mathrm{mg}$, and $125 \mu \mathrm{g}$ of digoxin daily.

An initial working diagnosis of GuillainBarré syndrome was made and he was admitted for investigations. Full blood count, plasma viscosity, random blood glucose, and liver function tests were within normal limits. The first clue of an electrolyte abnormality was provided by the electroencephalogram (ECG) which showed tall and peaked $\mathrm{T}$ waves and widened QRS complexes suggestive of hyperkalaemia (fig 1). This was confirmed by the concentrations of electrolytes and creatinine, which showed a sodium of $133 \mathrm{mmol} / 1$ and a potassium of $9.4 \mathrm{mmol} / \mathrm{l}$; the urea was 23.2 $\mathrm{mmol} / 1$ and creatinine $266 \mu \mathrm{mol} / 1$. When enalapril was first started, the creatinine was 126 $\mu \mathrm{mol} / 1$ and potassium $4.7 \mathrm{mmol} / \mathrm{l}$. Immediate treatment was instituted with glucose/insulin, calcium gluconate, and sodium bicarbonate with ECG monitoring. There was a satisfactory response to treatment with a gradual reduction in the potassium concentrations. Treatment was continued with calcium resonium and dietary restriction of potassium. Enalapril was discontinued.

The patient's weakness had begun to resolve almost immediately after the start of treatment and neurological examination was completely normal by the next morning. The potassium was $6.7 \mathrm{mmol} / \mathrm{l}$ at that stage. Neurophysiological studies and lumbar puncture which had been planned were therefore not carried out. At the time of discharge, the potassium was 5.5 $\mathrm{mmol} / \mathrm{l}$ and creatinine $202 \mu \mathrm{mol} / \mathrm{l}$. He remained well after discharge and in March 2000 had a sodium of $140 \mathrm{mmol} / \mathrm{l}$, a potassium of 4.8 $\mathrm{mmol} / \mathrm{l}$, and a creatinine of $180 \mu \mathrm{mol} / \mathrm{l}$. 


\section{Learning points}

- Electrolytes and an ECG should be obtained early in patients suspected of having the Guillain-Barré syndrome.

- Hyperkalaemia leading to muscle weakness can be caused by ACE inhibitors.

- Early treatment of hyperkalaemia usually reverses the paralysis.

\section{Discussion}

Our case highlights the importance of measuring electrolytes and recording an ECG in all patients with flaccid paralysis. Earlier case reports have commented on the fact that this form of hyperkalaemic paralysis is virtually indistinguishable clinically from the GuillainBarré syndrome. ${ }^{2358}$ In two cases where neurophysiological studies have been carried out, reduced nerve conduction velocities have been found suggesting nerve mediated weakness. ${ }^{23}$ Cerebrospinal fluid has been examined in four patients and has been normal in every case. ${ }^{23}{ }^{3}$ Most cases described earlier have had an onset of muscle weakness over days. In our patient, the muscle weakness was more abrupt in onset. ACE inhibitors inhibit the release of aldosterone and hence tend to increase plasma potassium concentrations by decreasing renal loss of potassium. This effect is most marked if they are used with potassium sparing diuretics or in the presence of pre-existing renal failure. The mechanism of hyperkalaemic paralysis is thought to be a consequence of the prolonged depolarisation of cell membranes caused by hyperkalaemia. ${ }^{12}$

The prognosis of hyperkalaemic weakness is usually very good. All but two patients described in the literature have improved rapidly with the treatment of hyperkalaemia either by glucose/insulin infusions, calcium, or dialysis. $^{2}{ }^{13}$ In our patient, muscle weakness started improving almost immediately after initiating treatment and neurological examination the next day was completely normal.

Our case is of special interest as it is the first reported case of muscle weakness caused by an ACE inhibitor in conjunction with mild renal impairment. Even though secondary hyperkalaemic paralysis was first described several years ago, ${ }^{4}$ it is uncommon and case reports such as this are useful to make clinicians more aware of this rare presentation of a common, often life threatening, electrolyte disturbance.

1 Hudson AJ, Ebers GC, Bulman DE. The skeletal muscle sodium and chloride channel diseases. Brain 1995;118:54763.

2 Evers S, Engelien A, Karsh V, et al. Secondary hyperkalaeEvers S, Engelien A, Karsh V, et al. Secondary hyperkalae-
mic paralysis. $\mathcal{F}$ Neurol Neurosurg Psychiatry 1998;64:24952 .

3 Naumann M, Reiners K, Schalke B, et al. Hyperkalaemia mimicking acute Guillain-Barré syndrome [letter]. $\mathcal{F}$ Neurol Neurosurg Psychiatry 1994;57:1436-7.

4 McNaughty RA, Burchell HB. Paralysis with potassium intoxication in renal insuffuciency. $\mathscr{F} A M A$ 1951;145:481-3.

5 Livingstone IR, Cumming WJK. Hyperkalaemic paralysis resembling Guillain-Barré syndrome [letter]. Lancet 1979; ii: $963-4$.

6 Shinotoh H, Hattori T, Kitano K, et al. Hyperkalaemic paralysis following traumatic rupture of the urinary bladder. 7 Neurol Neurosurg Psychiatry 1985;48:484-5.

7 Rado JP. Successful treatment of hyperkalaemic quadriplegia associated with spironolactone. International fournal of Clinical Pharmacology Therapy and Toxicology 1988;26:33945.

8 Udezue WO, Harrold BP. Hyperkalaemic paralysis due to spironolactone. Postgrad Med f 1980;56:254-5.

9 Freeman S, Fale AD. Muscular paralysis and ventilatory failure caused by hyperkalaemia. Br f Anaesth 1993;70:2267.

10 Jaffey L, Martin A. Malignant hyperkalaemia after amiloride/hydrochlorthiazide treatment [letter]. Lancet $1981 ; \mathbf{i}: 1272$.

11 McCarty M, Jagoda A, Fairweather P. Hyperkalaemic ascending paralysis. Ann Emerg Med 1998;32:104-7.

12 Singer GS, Brenner BM. Fluid and electrolyte disturbances In: Fauci AS, Braunwald E, Isselbacher KJ, et al, eds. Harrison's principles of internal medicine. New York: McGraw-Hill, 1998: 275-6.

13 Herman R, Rado J. Fatal hyperkalaemic paralysis associated with spironolactone. Arch Neurol 1966;15:74-7. 